\title{
Energy requirements in Chilean infants
}

\author{
G Salazar, F Vio, C García, E Aguirre, W A Coward
}

\begin{abstract}
Aim-To evaluate the energy requirements of breast fed infants.

Methods-The study was conducted in 17 healthy exclusively breast fed infants of normal birth weight (mean (SD) 3332 (280) g). Energy expenditure by the doubly labelled water method and milk intake by the dose to infant method were measured at 34 (4) days. A dose of $0.2 \mathrm{~g} / \mathrm{kg}$ deuterium oxide $(99.8 \%)$ and $2.0 \mathrm{~g} / \mathrm{kg} 10 \%{ }^{18} \mathrm{O}$ labelled water was given to the infants, and urine samples were collected for seven consecutive days after dosing.

Results-The mean (SD) weight of the infants during the period of evaluation was 4617 (343) $\mathrm{g}$ and weight gain 34.0 (7.5) g/day. Daily milk intake was 728 (101) g and its metabolisable energy content 2.71 $\mathrm{kJ} / \mathrm{g}$. The energy expenditure of the infants was 1205 (312) kJ/day and energy required for growth was 607 (130) $\mathrm{kJ} /$ day. When combined this produced an energy requirement of $391 \mathrm{~kJ} / \mathrm{kg} / \mathrm{day}$ for these infants.

Conclusion-These data agree with those from other studies in the United Kingdom and the United States and suggest that adequate growth can be achieved with $19.4 \%$ less energy than recommended by FAO/WHO/UNU.
\end{abstract}

(Arch Dis Child Fetal Neonatal Ed 2000;83:F120-F123)

Keywords: lactation; isotope dilution; breast milk intake; energy expenditure

Current nutritional guidelines for the energy requirements of children are based on observations of energy intake, ${ }^{1}$ but it is generally accepted that measurements of energy expenditure should be used. ${ }^{2}$ Most observations of energy expenditure have been reported for bottle fed infants, and few studies have been conducted in breast fed infants. ${ }^{3}$ Moreover, even fewer studies have been conducted in developing countries where other factors can influence the energy expenditure pattern and growth-for example, a study in Mexico in which energy expenditure in infants was higher than in infants in the United States. The authors speculated that this was caused by adverse environmental conditions. ${ }^{4}$ The present study was conducted in Santiago de Chile, where environmental pollution is one of the highest in Latin America. ${ }^{5}$

Energy expenditure can be measured by the doubly labelled water method, which allows energy expenditure of infants to be studied without interfering with their normal pattern of feeding, and the volume of breast milk consumed has been measured by the isotopic technique. ${ }^{6-8}$ Thus, by combining the doubly labelled water method for energy expenditure and the deuterium dilution technique for the measurement of breast milk volume, it is possible to calculate the metabolisable energy in milk consumed by exclusively breast fed infants, if the energy cost of growth is allowed for (metabolisable energy intake = total energy expenditure + cost of growth)

The objective of this study was to estimate energy expenditure (hence energy requirements) and milk intake in 1 month old exclusively breast fed infants by using isotopic methods, to compare them, and by allowing for the energy cost of growth, to calculate the energy density of the milk.

Subjects and methods

The study was carried out on 17 free living infants of low socioeconomic status in the south east of Santiago, Chile. The criteria for their selection were: age 1 month at the beginning of the study; birth weight more than 2900 g; exclusively breast fed; no congenital pathologies; and an APGAR score of 9 at five minutes. When the mothers had been informed about the experimental protocol and had agreed to follow it, they were asked to give written consent. The nutritional review board of the Institute of Nutrition and Food Technology and the ethical committee of the Sotero Del Rio Hospital approved the study. Table 1 gives the characteristics of the 17 infants studied.

When the infants were 1 month old, a nutritionist and a nurse visited their homes and, after confirming that the infants were exclusively breast fed, asked the mother to collect a sample of the infant's urine (spot sample). Infant's weight, height, tricipital skinfold, and arm and head circumferences, and mother's weight were recorded. Infants were weighed again at the end of the seven day measurement period. A record was kept of the small amounts of extra fluids ingested by the infant during the follow up visits for the sampling collection.

The day after baseline samples had been collected, a doubly labelled water dose $(0.2 \mathrm{~g} / \mathrm{kg}$ deuterium oxide $(99.9 \%)$ and $2.0 \mathrm{~g} / \mathrm{kg} 10 \%$ $\mathrm{H}_{2}^{18} \mathrm{O}$ ) was given to the baby to assess milk intake, body composition, and energy expenditure. For seven consecutive days after this dose, a nurse visited the house every other day to supervise the mother's collection of the daily

Table 1 General data of infants

\begin{tabular}{ll}
\hline Sex ratio $(\mathrm{M} / \mathrm{F})$ & $9 / 8$ \\
Birth weight $(\mathrm{g})$ & $3332(280)$ \\
Birth height $(\mathrm{cm})$ & $50.2(1.4)$ \\
Age at evaluation (days) & $34(4)$ \\
Weight at evaluation $(\mathrm{g})$ & $4509(401)$ \\
Height at evaluation $(\mathrm{cm})$ & $54.3(1.6)$ \\
Weight gain (g/day) & $34.0(7.5)$ \\
Breast milk intake (g/day) & $728(101)$ \\
\hline
\end{tabular}

Values are mean (SD). 
urine spot sample and the recording of the time of collection. The procedure was conducted according to the multipoint protocol described by Coward, ${ }^{9}$ and, to ensure linearity of the data, the first and last samples were collected by the nurse herself, who also checked on extra fluid intake and the infant's health.

Samples were stored in refrigerators or kept in a cold place in the house, and all urine samples were frozen thereafter at $-20^{\circ} \mathrm{C}$ until analysis.

CALCULATION OF MILK VOLUME

Breast milk volume was measured by the dose to infant method described by Coward et $a l^{10}$ and validated by others. ${ }^{11-13}$ Water turnover was used to calculate volume of milk consumed as follows: total water intake $=$ water output + water stored

Water output can be calculated as the product of total body water in the infant $\left(\mathrm{V}_{\mathrm{b}}\right)$ multiplied by the constant rate of disappearance of the deuterium from the body $\left(\mathrm{k}_{\mathrm{d}}\right)$, and this product corrected for isotopic fractionation (0.99). Baby's water volume, $\mathrm{V}_{\mathrm{b}}$, was evaluated by the weighed average of dilution volumes determined by $\mathrm{H}_{2}{ }^{18} \mathrm{O}(\mathrm{No})$ and ${ }^{2} \mathrm{H}_{2} \mathrm{O}(\mathrm{Nd})$ : $\mathrm{V}_{\mathrm{b}}=0.5(\mathrm{No} / 1.01+\mathrm{Nd} / 1.04)$.

The factors 1.01 and 1.04 correspond to the correction for overestimation of body water as the result of sequestration of both ${ }^{18} \mathrm{O}$ and deuterium in labile molecule sites. In addition, total water intake of the infant is also equal to the sum of water contained in milk plus additional non-milk water. Non-milk water can arise from both extra fluids given by the mother (water, juices, eventually formula) and nonoral water (environmental water influx). The daily records of the mother gave non-milk water intake during the period of evaluation, and environmental water influx was controlled for by multiplying total water intake by a correction factor of $0.937 .^{14}$ This correction factor took into consideration the fact that humidity and temperature factors in Santiago are those of a Mediterranean climate rather than a tropical country. Finally, milk volume was assessed, assuming a proportion of $96 \%$ of water after complete reduction of its solids. ${ }^{15}$

CALCULATION OF ENERGY EXPENDITURE

The method used to evaluate energy expenditure is similar to that used by others ${ }^{16} 17$ and has been successfully validated in preterm infants ${ }^{18}$ and infants after surgery, ${ }^{19}$ showing that energy expenditure from doubly labelled water does not differ from that measured by respiratory gas exchange. The multipoint method (seven days in this case) was used, halving the errors of the determination. ${ }^{9}$

Basically, when administering a doubly labelled water tracer (with ${ }^{18} \mathrm{O}$ and deuterium), deuterium is lost in water, and ${ }^{18} \mathrm{O}$ is lost in water and $\mathrm{CO}_{2}$. The deuterium rate constant $\left(\mathrm{K}_{\mathrm{d}}\right)$ represents water turnover rate, and the ${ }^{18} \mathrm{O}$ rate constant $\left(\mathrm{K}_{\mathrm{o}}\right)$ represents turnover of water plus $\mathrm{CO}_{2}$. The rate of $\mathrm{CO}_{2}$ production can be derived from the difference between the two rates, and energy expenditure is then calculated from $\mathrm{CO}_{2}$ production, using standard calorim-
Table 2 Body composition of infants

\begin{tabular}{ll}
\hline Average weight $(\mathrm{g})$ & $4617(343)$ \\
Total body water $(\mathrm{g})$ & $2997(341)$ \\
Total body water percentage & $64.9(5.2)$ \\
Body fat content $(\%)$ & $17.7(6.4)$ \\
Fat deposition $(\mathrm{g} /$ day) & $14.1(3.6)$ \\
Lean body mass deposition (g/day) & $19.6(4.5)$ \\
Protein deposition (g/day) & $1.96(0.5)$
\end{tabular}

Values are mean (SD).

Table 3 Energy requirements of infants

\begin{tabular}{ll}
\hline Energy expenditure (kJ/day) & $1205(312)$ \\
Energy stored (kJ/day) & $607(130)$ \\
Total energy required (kJ/day) & $1812(351)$ \\
Energy requirements $(\mathrm{kJ} / \mathrm{kg} /$ day) & $391(60)$
\end{tabular}

Values are mean (SD).

etry equations, which involve an estimate of the mean respiratory quotient, over the entire period of measurement.

The principal assumptions involved in the calculation are related to: (a) proportion of water fractionated, $(b)$ the fractionation factors that arise from the isotopic content in vapour/ liquid phases for both isotopes, and $(c)$ the conversion of the calculated rate of $\mathrm{CO}_{2}$ production into energy equivalent. The first factor depends mainly on the environmental conditions under which the measurement is performed and insensible water losses (respiratory and transepidermal). In relation to the proportion of water fractionated, a value of 0.15 was used, and to convert $\mathrm{CO}_{2}$ production rate into energy, a value of 0.85 was assumed for respiratory quotient. Standard errors of the measurement for each estimate were calculated as suggested by Coward et al . ${ }^{20}$

Analysis of the enrichment on deuterium and ${ }^{18} \mathrm{O}$ was performed at the Laboratory of Stable Isotopes of the Chilean Commission of Nuclear Energy. The samples were analysed in a Finnigan Mat $261\left({ }^{18} \mathrm{O}\right)$ and Micromass 602C (deuterium) isotope mass spectrometer (VG Isotopes Ltd, Cheshire, UK). Standards used were calibrated against the Vienna Standard Mean Ocean Water (V-SMOW), issued by the Laboratory of Standards (IAEA, Vienna, Austria) of the International Atomic Energy Agency.

\section{Results}

Table 1 shows the general data for the infants. It can be seen that they have normal birth weight and height, and their mean growth in weight and height in the first month followed the 50th percentile (National Center for Health Statistics). A mean (SD) weight gain of $34.0(7.5) \mathrm{g} /$ day corresponds to a milk intake of 728 (101) g/day, which was sufficient to provide for normal growth during this first month of life.

Table 2 gives data on body composition in the infants. The percentage body water in relation to weight is 64.9 , consistent with other studies and lower than values suggested by Fomon et al. ${ }^{21}$ The percentage body fat and rate of weight gain (34.0 (7.5) g/day) are in line with changes in the reference child ${ }^{21}$ during the first month of life.

Table 3 shows the measured daily energy expenditure: 1205 (312) kJ. The energy stored 
Table 4 Energy requirements determined in breast fed infants compared with $\mathrm{FAO} / \mathrm{WHO} / \mathrm{UNU}$ recommendation

\begin{tabular}{|c|c|c|c|c|c|}
\hline Reference & $\begin{array}{l}\text { Age } \\
\text { (days) }\end{array}$ & Weight $(g)$ & $\begin{array}{l}\text { TDEE } \\
\text { (kf/day) }\end{array}$ & $\begin{array}{l}\text { Metabolisable } \\
\text { energy intake } \\
\text { (kf/kg/day) }\end{array}$ & $\begin{array}{l}\text { Difference from } \\
\mathrm{FAO} / \mathrm{WHO} / \mathrm{UNU} \\
\text { recommendation } \\
(\%)\end{array}$ \\
\hline Lucas $e t a l^{7}$ & 35 & 4497 (107) & $1279(109)$ & 402 & 17.1 \\
\hline Wells \& Davies ${ }^{14}$ & $36(3)$ & $4540(480)$ & $1270(380)$ & 421 & 13.2 \\
\hline Butte $e t a l^{16}$ & $32(3)$ & $4654(734)$ & $1216(201)$ & 383 & 21.0 \\
\hline This work & & & $1205(314)$ & 391 & 19.4 \\
\hline $\mathrm{FAO} / \mathrm{WHO} / \mathrm{UNU}^{1}$ & & & & 485 & \\
\hline
\end{tabular}

Values are mean (SD).

TDEE, total daily energy expenditure.

in new tissue was calculated using values of $38.7 \mathrm{~kJ} / \mathrm{g}$ fat and $23.6 \mathrm{~kJ} / \mathrm{g}$ protein ${ }^{22}$, giving a total of energy stored of 607 (130) kJ/day. Daily energy requirements were obtained by adding together daily energy expenditure plus energy stored (1812 (351) kJ/day). Total energy requirement was $391(60) \mathrm{kJ} / \mathrm{kg} /$ day at 1 month of age.

Energy supplied by milk (728 g) was converted into metabolisable energy content assuming that $92 \%$ of milk is used in growth. This was compared with the amount of energy needed by infants at this age, which gave an energy content of milk of $2.71 \mathrm{~kJ} / \mathrm{g}(0.65 \mathrm{kcal} /$ g).

In table 4 , the present results are compared with the energy requirements found for similar infants in the United Kingdom and United States, with the same type of measurements.

\section{Discussion}

Stable isotopes have proved extremely useful for field studies on breast milk intake and body composition. ${ }^{8}{ }^{15}$ It is also possible to measure energy expenditure in infants. The evaluation of energy metabolism in free living unrestricted infants is of particular importance for setting future energy recommendations and to study the effect of diet on energy metabolism, energy balance, and growth. ${ }^{23}$ Establishing energy requirements by the doubly labelled water method for energy expenditure and calculating the energy needed for adequate growth (metabolisable energy) are of particular relevance in breast fed infants.

The advantages of the doubly labelled water method are the non-invasive character of the measurements, the relative ease with which it can be applied to infants in field conditions, and the possibility of combining this type of evaluation with others, such as anthropometry, milk intake, and body composition, providing valuable information on energy balance and growth. The main disadvantages are the high cost of the isotopes, in particular ${ }^{18} \mathrm{O}$, and the complexity of the laboratory measurements, which require a mass spectrometer and trained personnel.

To our knowledge, this is the first energy expenditure study carried out in 1 month old infants in Latin America. Previous studies were conducted in protein malnourished 3-18 month old children in an inpatient metabolic ward in Lima, Peru ${ }^{24}$, the above mentioned study in 4 and 6 month old Mexican infants, ${ }^{4}$ and also similar studies carried out in Gambia. $^{25}$
The infants in this study were comparable with those in previous studies in the United Kingdom ${ }^{713}$ and United States ${ }^{16}$ with respect to birth weight, healthy nutritional status at the time of evaluation, breast feeding status, and adequate rate of growth. In this study, daily total energy expenditure in infants is in close agreement with previous results in 1 month old infants from developed countries, as shown in table 4 .

Estimates of energy requirement have been based on energy intake, ${ }^{1}$ and the recommendations for this age group are $485 \mathrm{~kJ} / \mathrm{kg} /$ day. The energy requirements determined for these Chilean infants (391 kJ/kg/day) are $19.4 \%$ lower than the FAO/WHO/UNU recommendations, which is also in agreement with incoming results from different groups of researchers, suggesting that adequate growth may be sustained on a smaller supply of energy than recommended at present. In this study, it is also clear that milk intake is sufficient to provide the necessary energy for normal growth during the first month of life. This fact is relevant for many developing countries, stressing the necessity to continue to promote exclusive breast feeding during the first months of life. For many developing countries, and most developed countries, where obesity is an important public health and nutrition problem, it is also important to establish the real energy requirements in order to avoid excess intake, and thereby prevent obesity and chronic diseases from early childhood.

$1 \mathrm{FAO} / \mathrm{WHO} / \mathrm{UNU}$. Energy and protein requirements: report of a joint FAO/WHO Ad Hoc Expert Committee. WHO Technical Report Series 724. Geneva: WHO, 1985.

2 Buyckx M, Dupont JL, Durnin JVGA, et al. Report of the working group on general principles of assessing energy requirements. Eur f Clin Nutr 1996;50(suppl 1):S186-7.

3 Butte NF. Energy requirements of infants. Am f Clin Nutr 1996;50(Suppl 1):S24-36.

4 Butte NF, Villalpando S. Wong WW, Flores-Huerta S, Hernandez-Beltran, Smith EO. Higher total energy expenditure contributes to growth faltering in breast-fed infants living in rural Mexico. $\mathcal{F}$ Nutr 1993;123:1028-35.

5 Pino P, Oyarzún M, Walter T, von Baer D, Romieu I. Indoor air pollution in South Eastern Santiago. Rev Med Chil 1998;126:367-74.

6 Coward WA, Cole TJ, Gerber H, Roberts SB, Fleet I. Water turnover and the measurements of milk intake. Pflügers Arch 1982;393:344-7.

7 Lucas A, Ewing G, Roberts SB, Coward WA. How much energy does the breast fed infant consumes and expends? BMF 1987;295:75-8.

8 Vio F, Salazar G, Infante C. Smoking during pregnancy and lactation and its effects on breast-milk volume. Am $\mathcal{F}$ Clin Nutr 1991;54:1011-16.

9 Coward WA. The doubly labelled water $\left({ }^{2} \mathrm{H}_{2}{ }^{18} \mathrm{O}\right)$ methods. Principle and practice. Proc Nutr Soc 1988;47:209-18.

10 Coward WA, Sawyer MB, Whitehead RC, Prentice AM, Evans J. New method for measuring milk intakes in breast-fed babies. Lancet 1979;2:13-14

11 Lucas A, Ewing G, Roberts S, Coward W. Measurement of milk intake by deuterium dilution. Arch Dis Child

12 Vio F, Infante C, Lara W, Mardones-S F, Rosso P. Validation of the deuterium dilution technique for the measurement of the deuterium dilution technique for the measurement
of fluid intake in infants. Human Nutrition: Clinical Nutrition 1986;40C:327-33.

13 Fjeld CR, Brown KH, Schoeller DA. Validation of the deuterium oxide method for measuring average daily milk intake in infants. Am f Clin Nutr 1988;48:671-9.

14 Wells KCK, Davies PSW. Correction for environmental water influx in measurement of milk volume intake by deuterium turnover in infants. Early Hum Dev 1995;41:177-82.

15 Coward WA, Cole TJ, Sawyer MB, Prentice AM. Breastmilk intake measurement in mixed fed infants by administration of deuterium oxide to their mothers. Human Nutrition: Clinical Nutrition 1982;36C:141-8.

16 Butte N, Wong WW, Ferlic L, Smith OE, Klein PD, Garza C. Energy expenditure and deposition of breast-fed and formula-fed infants during early infancy. Pediatr Res 1990;28:631-40. 
17 Davies PSW, Ewing G, Lucas A. Energy expenditure in early infancy. Br f Nutr 1989;62:621-9.

18 Roberts SB, Coward WA Schingenseipen $\mathrm{KH}$, et al. Comparison of the doubly labelled water $\left({ }^{2} \mathrm{H}_{2}{ }^{18} \mathrm{O}\right)$ method with indirect calorimetry and a nutrient balance study for simultaneous determination of energy expenditure, water intake and metabolisable energy intake in pre-term infants. Am F Clin Nutr 1986;44:315-22.

19 Jones PHJ, Winthrop AL, Scholler DA, et al. Validation of doubly labelled water for assessing energy expenditure in infants. Pediatr Res 1987;21:242-6.

20 Coward WA, Roberts SB, Cole TJ. Theoretical and practical method for the measurement of carbon dioxide production rate in man. Eur f Clin Nutr 1988;42:207-12.
21 Fomon SJ, Haschke F, Ziegler EE, et al. Body composition of reference children from birth to age 10 years. Am 7 Clin Nutr 1982;35:1169-75.

22 Roberts SB, Young VR. Energy cost of fat and protein deposition in the human infant. Am f Clin Nutr 1988;48:951-5.

23 Davies PSW. Energy requirements and energy expenditure in infancy. Eur 7 Clin Nutr 1992;46(suppl 4):S29-35.

24 Fjeld CR, Schoeller DA, Brown KH. A new model for predicting energy requirements of children during catch-up growth developed using doubly labelled water. Pediatr Res 1989;25:503-8.

25 Vasquez-Velásquez L. Energy expenditure and physical activity of malnourished Gambian infants. Proc Nutr Soc $1988 ; 47: 233-9$. 